\title{
Braille learning: Effects of symbol size
}

\author{
SLATER E. NEWMAN and MARILYN B. KINDSVATER \\ North Carolina State University, Raleigh, North Carolina \\ and \\ ANTHONY D. HALL \\ IBM Corporation, Research Triangle Park, North Carolina
}

\begin{abstract}
Learning the name for braille symbols was facilitated by the presence of large symbols on study trials when standard-size symbols were present on test trials, and by the presence of large braille symbols on test trials. These effects were found to be independent of the discriminability of the set of items for which the names were to be learned.
\end{abstract}

Previous research has shown that the rate of learning the names for each of a set of items is ordinarily a direct function of the degree to which the items are discriminable from one another (McGuire, 1961; Newman et al. 1982; Plotkin, 1943). The present experiment was done to provide additional information in this domain.

In a prior experiment from our laboratory (Newman et al., 1982; Experiment 3), subjects were given the task of learning the names for the symbols of the first 10 letters of the alphabet (i.e., A-J) presented during study trials for either visual or haptic examination. In addition, for half of the subjects, the items were presented in standard braille (the dimensions for the $2 \times 3$ matrix constituting the standard braille cell are approximately $4 \times 6 \mathrm{~mm}$ ), and for the rest of the subjects, the items were presented in large braille (for which the size of the braille cell is approximately $6 \times 9 \mathrm{~mm}$ ). On test trials, all subjects were tested haptically with standard braille items. Size of the braille cell during study trials was found to facilitate learning only for subjects who studied the items haptically. ${ }^{1}$

The present study was performed to ascertain whether this effect might be a function of the size of the braille cell during test trials. In addition, two sets of symbols were used, those for A-J and those for K-T. The symbols for K-T have been shown to be harder to discriminate from one another than those for A-J (Newman, Hall, Foster, \& Gupta, 1984, Experiment 1). The braille symbols for the letters A-T are shown in Figure 1.

\section{METHOD}

A $2 \times 2 \times 2$ design was used in which study size (standard or large braille), test size (standard or large braille), and item set (A-J or K-T)

The authors express their appreciation to John Calloway, Principal of the Governor Morehead School for the Blind, Raleigh, NC, for the use of Thermoform equipment. A paper reporting the results of this experiment was presented at the 1984 meeting of the Eastern Psychological Association in Baltimore. Reprints of this article may be obtained by writing to Slater E. Newman, Department of Psychology, Box 7801, North Carolina State University, Raleigh, NC 27695-7801.

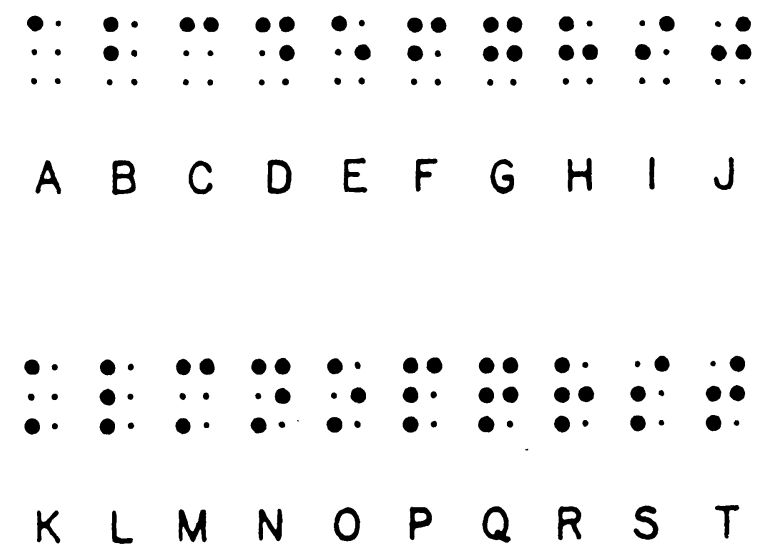

Figure 1. Braille symbols for the letters A through T.

were manipulated. A study-test procedure was used; each of the five study trials was followed by a test trial. On study trials, each symbol was presented for haptic examination for $10 \mathrm{sec}$ along with auditory presentation of its letter name. On test trials, the subjects were given $10 \mathrm{sec}$ to examine each item haptically and to call out its letter name. Two different sets of orders of the items were used, each for half of the subjects in each treatment. In each order set, 10 different orders were employed.

There were 80 sighted male subjects, all of whom were enrolled in the introductory course in psychology at North Carolina State University. All were right-handed and were run individually. The subjects used the index finger of the right hand to examine each item haptically on study and test trials. This hand was covered throughout the experiment to preclude visual examination of the items. A counterbalancing procedure was used in assigning subjects to the treatments.

Table 1

Mean Total Correct Responses for Each Treatment

\begin{tabular}{cccc}
\hline & & \multicolumn{2}{c}{ Test Size } \\
\cline { 3 - 4 } Item Set & Study Size & Standard & Large \\
\hline \multirow{2}{*}{ A-J } & Standard & 15.60 & 24.90 \\
& Large & 23.50 & 25.30 \\
\multirow{2}{*}{ K-T } & Standard & 8.00 & 13.90 \\
& Large & 11.40 & 13.40 \\
\hline
\end{tabular}

Note-Maximum score was 50.00 . 
Table 2

Rank-Order Correlations Between Paris of Treatments for Item Difficulty and Type of Error

\begin{tabular}{|c|c|c|c|c|c|c|c|c|}
\hline \multicolumn{2}{|c|}{ Treatment } & & \multicolumn{2}{|c|}{ Treatment } & \multirow{2}{*}{\multicolumn{2}{|c|}{ Items Correct* }} & \multirow{2}{*}{\multicolumn{2}{|c|}{ Type of Error** }} \\
\hline Study & Test & & Study & Test & & & & \\
\hline size & size & & size & size & A-J & $\mathrm{K}-\mathrm{T}$ & A-J & $\mathrm{K}-\mathrm{T}$ \\
\hline Regular & Regular & $\&$ & Regular & Large & .911 & .590 & .530 & .356 \\
\hline Regular & Regular & $\&$ & Large & Regular & .903 & .893 & .658 & .370 \\
\hline Regular & Regular & $\&$ & Large & Large & .903 & .584 & .642 & .264 \\
\hline Regular & Large & $\&$ & Large & Regular & .837 & .713 & .599 & .368 \\
\hline Regular & Large & $\&$ & Large & Large & .874 & .854 & .627 & .546 \\
\hline Large & Regular & $\&$ & Large & Large & .952 & .780 & .699 & .475 \\
\hline
\end{tabular}

*For items correct, all correlations were positive and significant [in all cases, rho(8) $>.58, p<.05$ ]. **For type of error, all correlations were positive and significant [in all cases, rho(88) $>.26, p<.01]$.

\section{RESULTS}

The means for total correct over the five trials for each of the eight treatment conditions are presented in Table 1. A repeated measures analysis of variance for number correct on each trial (with the effects of blocks removed) gave the following significant effects: item set $[\mathrm{F}(1,67)=$ $55.83, \mathrm{p}<.001]$, test size $[\mathrm{F}(1,67)=11.11, \mathrm{p}<.01]$, study size $\times$ test size $[F(1,67)=4.00, p<.05]$, trials $[\mathrm{F}(4,268)=54.72, \mathrm{p}<.001]$, and item set $\times$ trials $[\mathrm{F}(4,268)=4.56, \mathrm{p}<.01]$. For the between-subjects effects, $\mathrm{MSe}=8.13$; for the within subjects effects, MSe $=1.54$. The only other effect to approach significance was that for study size $(p=.054$.)

Further analysis showed that the mean for the A-J set was higher than that for the K-T set, with the difference increasing over training. Duncan's cluster analysis indicated that (1) the presence of large symbols during test trials was facilitative, especially when standard symbols were present during study trials, and (2) the presence of large symbols on study trials facilitated learning only when standard symbols were present on test trials.

Correlations were done for order of difficulty of the items within each item set for each pair of treatments (see Table 2). Coefficients ranged from .584 to .952 . All were positive, and all were significant $(\mathrm{p}<.05)$. In addition, a confusion matrix was constructed for each treatment for each item set. Again correlations were obtained between each pair of treatments for each item set (see Table 2). Coefficients ranged from .264 to .699 , and, again, all were positive, and all were significant $(\mathrm{p}<.01)$.

\section{DISCUSSION}

The results of this experiment show that performance during learning the names for braille symbols is facilitated if large braille symbols are present during test trials, particularly if standard braille symbols are present during study trials; in addition, the presence of large braille symbols during study trials is facilitative when standard braille symbols are present during test trials. These latter results replicate our previous findings (Newman et al., 1982), as does the faster learning of the A-J than the K-T sets (Newman et al., 1984). Rather surprisingly, however, the effects of size of the braille symbols during study trials and during test trials were each found to be independent of the discriminability of the set of symbols for which the names were to be learned.

The results for confusion errors accord with previous findings (Newman et al., 1984; Newman et al., 1982), as do the results for item difficulty. The latter also are similar to those reported by Loomis (1982). All of these findings indicate that the order of difficulty of items and the pattern of errors are each relatively stable across a variety of experimental conditions.

On the basis of a survey of British braille teachers of adventitiously blind adults, Tobin (1971) reported that a majority of the teachers (i.e., $53 \%$ ) favored using large braille symbols during the early stages of instruction; the remainder favored using standard-size braille. Our results and those from a previous experiment (Newman et al., 1982) appear to support the use of large braille during early training. Our results suggest, also, that it might be desirable to use large braille for all items both on study trials and on test trials, at least early during training. Further research is required, however, to determine when and how the transition from large to standard braille can best be made.

\section{REFERENCES}

Loomis, J. M. (1982). Analysis of tactile and visual confusion matrices. Perception \& Psychophysics, 31, 41-52.

MCGuIRE, W. J. (1961). A multiprocess model for paired-associate learning. Journal of Experimental Psychology, 62, 335-347.

Newman, S. E., Hall, A. D., Foster, D. L., \& Gupta, V. G. (1984). Learning as a function of haptic discriminability among items. American Journal of Psychology, 97, 359-372.

Newman, S. E., Hall, A. D., Ramseur, C. J., Foster, D. L., GoldSton, D. B., DeCAmp, B. L., Granberry-Hager, S. P., Lockhart, J. L., SAWYeR, W. L., \& WhiTe, J. E. (1982). Factors affecting the learning of braille. Journal of Visual Impairment and Blindness, 77, 59-64.

Plotkin, L. (1943). Stimulus generalization in Morse code learning. Archives of Psychology, 40, 287.

Toвin, M. H. (1971). Programmed instruction and braille learning. Birmingham, England: Research Centre for the Education of the Visually Handicapped.

\section{NOTE}

1. It is assumed that the items presented visually during study trials were readily discriminable from one another; thus, under that condition, variation in the size of braille had no effect.

(Manuscript received for publication January 31, 1985.) 